EESTI NŜ̀ TEADUŚTE AKADEEMIA TOIMETISED. V KÖIDE

BIOLOOGILINE SEERIA. 1956, NR. 3

ИЗВЕСТИЯ АКАДЕМИИ НАУК ЭСТОНСКОИ ССР. ТОМ V

СЕРИЯ БИОЛОГИЧЕСКАЯ. 1956, 수 3

\title{
KUIVENDATUD SIIRDESOOMETSADE LAGERAIETE ÖKOLOOGILISED TINGIMUSED JA NEILE VASTAVAD METSAKULTUURIDE RAJAMISE MEETODID
}

\section{U. RIISPERE}

Umbkaudsete arvestuste järgi kannatab Eesti NSV metsadest liigniiskuse all 315000 ha ehk $40 \%$ riigimetsafondimaadest. Ebasoodsate niiskus- ja toitumistingimuste tõttu kasvavad niisugustel aladel kidurad ja vähetootlikud puistud (soostunud ja soometsad). Niiskustingimuste parandamiseks ja seeläbi metsatootlikkuse suurendamiseks viiakse liigniiskuse all kannatavais metsades läbi kuivendustöid. Eesti NSV territooriumil seni läbiviidud sellealased uurimused näitavad, et kuivendamine tõstab tunduvalt metsa tootlikkust. Seepärast pöönavad meie partei ja valitsus suurt tähelepanu metsamaade melioratsiooniküsimustele.

Soode põhitüüpidest (madalsood, siirdesood ja rabad) on metsamajanduse seisukohalt kõige suurem tähtsus siirdesoodel. Rabade kasutuselevõtmine on seotud väga põhjalike ja seetõttu ka väga kulukate melioratsioonitöödega (intensiivne kuivendamine, põletamine, lubjastamine, väetamine jne.), madalsood seevastu kuuluvad oma suure toitainetesisalduse tõttu (pärast kuivendamist) põhiliselt põllumajanduslikule kasutamisele. Seetõttu on mõistetav, miks möödunud sajandi lōpul ja käesoleva sajandi algul, kui hakati suuremal määral soid kuivendama, olid peamisteks metsanduslikeks kuivendusobjektideks just siirdesoometsad. Praegu kasvavad neil aladel eeskätt männipuistud, kus peale männi esineb veel kuuske (tavaliselt $1 / 10$ $-1 / 20$ puistu koosseisust tagavara järgi) ja sookaske $\left(1 /{ }_{10}-2 / 10\right.$ puistu koosseisust). Varemkuivendatud siirdesoometsadest on paljud jöudnud raieküpsesse ikka. Neid leidub küllaltki suurepinnaliselt üle kogu Eesti NSV, näiteks Jõhvi metsamajandi Oru metskonnas, Kurista metsamajandi Vaimastvere metskonnas, Tartu metsamajandi Kaiavere metskonnas, Võru metsamajandi Sõmerpalu metskonnas, Viljandi metsamajandi-Loodi metskonnas, Järvamaa metsamajandi Väätsa metskonnas ja mujal. Nendes on teostatud pialju lageraieid.

Pärast metsa raiumist toimub puuliikide vaheldus. Raielangid uuenevad looduslikult peamiselt sookasega, mille tõttu käsitletavatele aladele männipuistute asemele tekivad sookasepuistud. Spetsiaalselt sellele küsimusele on pühendatud Kollisti (1953) töö, mis põhineb tema poolt Sõmerpalu katsemetskonnas teostatud uurimistel. Rahvamajanduse seisukohalt ei saa pidada säärast puuliikide vaheldust soovitavaks, sest kuivendatud siirdesoodel on sookase tootlikkus männi ja kuusega võrreldes tunduvalt väiksem (Hainla, 1955). 
Ebasoovitavat puuliikide vaheldust on võimalik vältida kasutades kunstlikku metsauuendamist, kultiveerides kuivendatud siirdesoometsade lageraielankidele mändi ja kuuske, mis on neil kasvukohtadel osutunud hea tootlikkusega puuliikideks.

Metsakultuuride rajamine kirjeldatud kasvukohtadele on väga raske ja keerukas ülesanne, mille lahendamine sageli on lõppenud ebaõnnestumisega. Seejuures on kultuuride arengus kõige raskem nende juurdumise faas (esimesed laastad pärast kultiveerimist), millal puutaimede kasvuks ebasoodsad ökoloogilised tingimused mõjuvad kõige laostavamalt. Metskondade praktikas, kus on tegeldud kuivendatud siirdesoometsade raiestike kultiveerimisega, esineb sagedasti kultuuride madal kordaminek või hukkumine (näit. Oru, Vaimastvere ja Sõmerpalu metskonnas). See ei ole imekspandav, sest kuni viimase ajani oli taoliste alade jaoks kultuuride rajamise ja hooldamise agrotehnika välja töötamata. Seetõttu ei anna olemasolevad õpikud ega instruktsioonid juhiseid kuivendatud soodele metsakultuuride rajamiseks.

Uurimused näitavad, et kultuuride hukkumise või madala kordamineku põhjuseks ei ole turvasmulla väike toitainetesisaldus. Ka muldade reaktsioon ( $\mathrm{pH} 4-5$ ) ei mõju puude kasvule ebasoodsalt. Tulenevalt pikaajalise kuivenduse môjust, on turbalasundi pealmine kiht hästi lagunenud (lagunemisaste $60-70 \%$ ) ja sõmerstruktuurne ning seal leidub taimedele kättesaadavaid ühendeid küllaldasel hulgal.

Tabelist 1 näeme, et pikaajalise kuivenduse tagajärjel tõuseb tuhasuse protsent turbalasundi pealmises kihis väga kõrgele. Tuhasuse protsent aga iseloomustab teadupärast hästi turvasmulla viljakust.

Tabel 1

Turba tuhasisaldus kuivendatud siirdesoometsade raielankidel Vaimastvere ja Oru metskonnas (1954. a.)

\begin{tabular}{|c|c|c|c|c|}
\hline Asukoht & 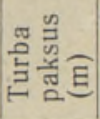 & $\begin{array}{l}\text { Pōhjavee } \\
\text { sügavus } \\
\text { (cm) }\end{array}$ & $\begin{array}{l}\text { Proovi vōtmise } \\
\text { sügavus }(\mathrm{cm})\end{array}$ & $\begin{array}{c}\text { Tuhasus } \\
(\%)\end{array}$ \\
\hline $\begin{array}{l}\text { Vaimastvere metskond, kvartaal } \\
98,1953 \text {. a. raielank } \\
\text { Oru metskond, kvartaal } 109 \text {, } \\
\text { 1953. a. raielank }\end{array}$ & 3,7 & $\begin{array}{l}41 \\
11 \\
30 \\
10\end{array}$ & $\begin{array}{c}0-15^{*} \\
15-25 \\
0-10^{*} \\
10-25 \\
0-10^{*} \\
10-25 \\
25-40 \\
0-6^{*} \\
6-20 \\
20-40\end{array}$ & $\begin{array}{r}15,15 \\
10,63 \\
12,43 \\
11,63 \\
21,86 \\
10,85 \\
6,10 \\
17,21 \\
11,97 \\
7,78\end{array}$ \\
\hline
\end{tabular}

*' Pealmine hästi lagunenud sõmerstruktuurne turvasmuld, mis teravalt eraldub selle all asuvast plinkjast turbalasundist.

Taimede kasvuks vajalike ainete küllaldast esinemist võib järeldada ka vanemate puistute, samuti noorendike heast kasvust ning lageraiete lopsakast taimkattest.

Peamised ebasoodsad ökoloogilised tegurid, mis põhjustavad metsakultuurides suurt väljalangevust ning millega tuleb võidelda kultuuride rajamisel ja nende kordamineku kindlustamisel, on: 1) pärast metsa raiumist tekkiv lopsakas taimkate, 2) külmakohrutus kevad- ja sügisperioodil, 3) sageli ebasoodsad niiskustingimused, 4) ebasoodsad temperatuuritingimused maapinnal ja maapinnalähedases õhukihis. Alljärgnevas käsitleme nende esinemist ja mõju. 
Taimkate. Kuivendatud siirdesoode raieküpsetes metsades moodustavad alataimestiku peamiselt metsasamblad (Hylocomium proliferum, Pleurozium Schreberi, Dicranum undulatum, Rhytidiadelphus triquetrus jt.), varjulembesed rohttaimed - leseleht, ümaralehine ja rohekas uibuleht, laanelill, jänesekapsas, ohtene sõnajalg, naistesõnajalg jt. parematele kasvukohtadele iseloomulikud taimed. Lisaks mainitud liikidele leidub veel rohkesti pohla ja vähem mustikat. Mõnedel juhtudel esineb kraavilähedastes koh: tades tiheda vaibana katekold. Alusmetsas domineerib paakspuu, millele lisanduvad tavaliselt pihlakas ja kadakas.

Nõrgalt kuivendatud (kralavist kaugemal asuvatel) aladel esineb turbasamblaid, harilikku jōhvikat, tuppvillpead jt. rabadele iseloomulikke taimi.

Metsa raiumisjärgsel suvel metsasamblad ja varjulembesed rohttaimed enamikus surevlad ning juba teisel raiumisjärgsel vegetatsiooniperioodil

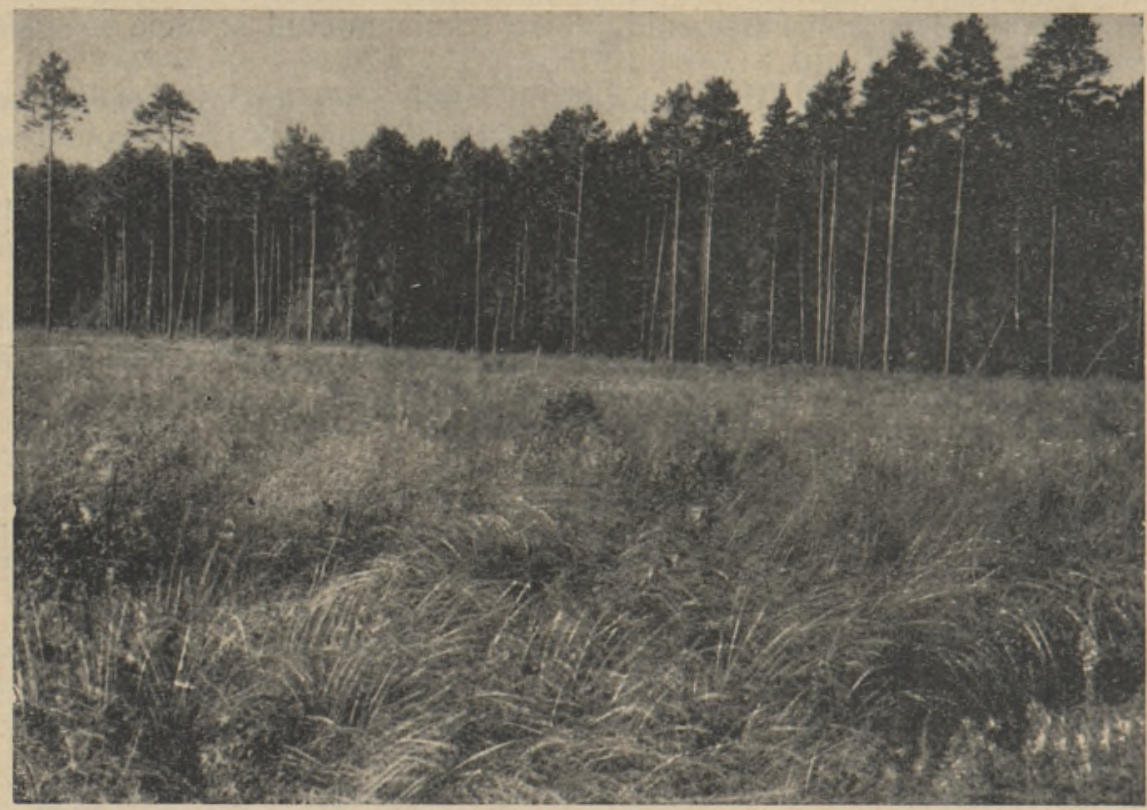

Joon. 1. Vohav taimkate kuivendatud siirdesoometsa lageraielangil teisel raiumisjärgsel suvel Oru metskonnas.

tekib tihe ja lopsakas valgusnõudlik taimkate, milles valdavatena esinevad sinihelmikas, luha-kastevars, sookastehein, metskastik, vaarikas, põdrakanep, roosa ja soo-pajulill, tarnad jt., mis moodustavad kõrge ja tiheda katte (joon. 1). Põõsastest domineerib paakspuu. Tekkima hakkab ka sookase tihe looduslik uuendus, mis esialgu küll erilist tähtsust metsakultiveerimise seisukohalt ei oma.

Turvasmuldade suurest lämmastikusisaldusest tingituna on taimede vegetatiivne kasv väga intensiivne. Nii kasvab põdrakanep sageli üle $2 \mathrm{~m}$ kõrguseks, samuti võib ületada inimese pikkuse sinihelmikas. Sookastehein ei saavuta küll niisugust kõrgust, kuid ta katab maapinda tiheda, vilditaolise kihina, mis noorte okaspuutaimede seisukohalt on veelgi ohtlikum.

Liikidevaheline võitlus okaspuutõusmete ja rohttaimestiku vahel avaldub neil raielankidel kõige tugevamal kujul. Ilma inimese vahelesegamiseta lōpeb see (eriti männi puhul) tavaliselt rohttaimestiku võiduga. Ka põdrakanep, mis on metsanduslikus kirjanduses üldiselt tunnustust leidnud 
puutaimede kasvu soodustava taimeliigina (turvestajana), takistab kuivendatud siirdesoode lageraietel oma äärmiselt vohava arengu tõttu noorte puutaimede kasvu, viies neid hävimiseni.

Rohttaimestikku ei teki kändude ümber asetsevail mikrokõrgendikel, mis jäävad kattunuks metsasammaldega, paluka ja leesikaga, või üldse taimkatteta. Pikemaks ajaks jäävad rohttaimestiku-vabaks ka katekollaga tihedalt kaetud kohad. Samuti ei levi lämmatav rohukate nõrgema kuivendusega kohtades turbasambla mätastele.

Kuna väärtuslikud okaspuud - mänd ja kuusk tuleb sisse viia kultiveerimise teel, peab lopsakat taimkatet kui olulist tegurit arvestama kogu agrotehnilise kompleksi (kultuuride rajamise aja, maapinna ettevalmistamise viisi, kultiveerimise viisi, kultiveerimise materjali ja hooldamise vōtete) väljatöötamisel.

Külmakohrutus. Esineb peamiselt suure veemahutavuse ja sisaldusega (suure kolloidide sisaldusega) muldadel, s. o. savi- ja turvasmuldadel. Seetõttu on ta väga oluline kultuuride kordaminekut vähendav ja sageli hukkumist pōhjustav tegur kuivendatud siirdesoode lageraietele rajatud okaspuukultuurides. Kohrutamise all kannatavad nii külvi kui ka istutamise teel rajatud kultuurid.

Kirjanduse andmed kui ka autori poolt teostatud vaatlused näitavad, et ühel ja samal kasvukohal oleneb külmakohrutuse esinemine mitmetest teguritest.

1. Külmakohrutuse oht on suurem mulla kôrgema niiskussisalduse puhul (välja arvatud juhul, kui maapind on kaetud veega). Kuivemas mullas takistab jääkristallide kasvu veepuudus.

2. Külmakohrutus ei teki taimkattega kattunud (kamardunud) või ka surnud kattega maapinnas. Juba 3-4 cm paksune metsakõdu kiht võib vältida mullas jääkristallide tekkimist.

3. Tunduvalt suurendab külmakohrutuse ohtu mulla segamine ja kobestamine. Sellest järeldub ka, miks meie kuivendatud siirdesoodele rajatud metsakultuurid enamikus on kannatanud külmakohrutuse all. Maapinna ettevalmistamine lappidena tavalisel viisil (mis seisneb kamara kõrvaldamises ja lapi põhja kobestamises) suurendab külmakohrutuse ohtu.

4. Turvasmuldade puhul on kohrutamisohtlikumad rohkemlagunenud turbad. Seevastu vähemlagunenud turvas ei allu nii kergesti kohrutamisele. Kui kuivendatud siirdesoo hästilagunenud turvasmuldadel asuvates (näit. Oru ja Vaimastvere metskonna) kultuurides on kohrutamine tavaline nähtus, siis kuivendatud rabadele (näit. Tallinna metsamajandi Viimsi metskonna Rae rabale) rajatud katsekultuuride puhul ei ole ta esinenud.

Kohrutamise ohtu arvestades tuleb käsitletavatel aladel kasutada võimalikult kohrutamiskindlaid kultuuride rajamise meetodeid. Need seisnevad peamiselt maapinna ettevalmistamisviisi õiges valikus. Nimelt ei tohi eemaldada surnud ega elusat katet ja kobestada maapinda. Vastav maapinna ettevalmistamisviis omakorda tingib kultiveerimisviisi, sest raske on kindlustada külvide kordaminekut ettevalmistamata maapinna puhul ja veel suure rohukasvu hädaohu korral. Külvile tuleb seetðttu eelistada istutamist, sest istutamisel on kultuuri viidavate taimede juured tugevamad ja tungivad sügavamale mulda ning ei paisku seepärast nii kergesti kohrutamise teel mullast välja kui külvitōusmed.

Niiskustingimused. Mulla niiskustingimused kuivendatud siirdesoometsades ei ole ühtlased. Nad sõltuvad suurel määral kraavide tihedusest, sügavusest ja korrashoiust. Meil olemasolevad vanemad kuivendussüsteemid on sageli hõredad, mistõttu kuivendatud soodeks nimetatavail aladel 
(näit. Oru ja Vaimastvere metskonnas) moodustavad suure osa kohad, kus esinevad veel puude kasvuks ebasoodsad liigniiskuse tingimused. Nii võivad ühe ja sama kuivendatud soomassiivi erinevatel raielankidel või ühe ja sama raielangi erinevatel osadel (mitmesugusel kaugusel kraavist) esineda küllalt lahkuminevad niiskustingimused.

Kraavi lähedal on tavaliselt mullaniiskus puutaimede kasvuks soodne, kuid esineda võivad ka mulla liigkuivuse tingimused. Peaasjalikult kahjustab see külve, kuna läbi kuivab tavaliselt kõige pealmine, mõ̃ne sentimeetri paksune mullakiht, mis kutsub esile kas seemnete mitteidanemise või siis tõusmete hukkumise. Kraavist kaugemal olevatel langiosadel võivad samal ajal puukesed kannatada liigniiskuse all. Väga varieeruvad on niiskustingimused ka mikroreljeefi mitmesugustel osadel.

Millist mõju avaldab turvasmulla erinev niiskussisaldus noorte mändide ja kuuskede kasvule, näitavad vegetatsioonikatsed, mis autori poolt korraldati ENSV TA Zooloogia ja Botaanika Instituudi metsasektoris männija kuusetõusmete kasvuks minimaalse, optimaalse ja maksimaalse turvasmulla niiskussisalduse väljaselgitamiseks.

Tabelis 2 on esitatud rida andmeid 1954. a. katsete tulemuste kohta (külv viidi läbi 25. juunil, esimesed tõusmed ilmusid 2. juulil ja koristamine toimus 4.-6. oktoobrini).

Tabel 2

Turvasmuldade mitmesuguse niiskuse juures kasvatatud männi- ja kuusetōusmete keskmised maapealsete osade toores- ja kuivkaalud ning okaste klorofüllisisaldus (1954. a. vegetatsioonikatsete materjalidel)

\begin{tabular}{|c|c|c|c|c|c|c|c|c|c|c|}
\hline \multicolumn{3}{|c|}{$\begin{array}{c}\text { Turvasmulla } \\
\text { niiskussisaldus }\end{array}$} & \multicolumn{4}{|c|}{ - Kuusk } & \multicolumn{4}{|c|}{ Mänd } \\
\hline 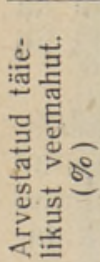 & 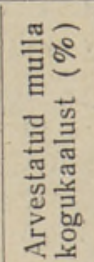 & 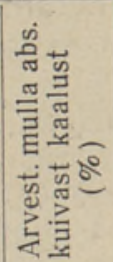 & 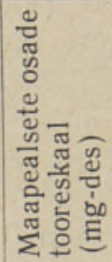 & 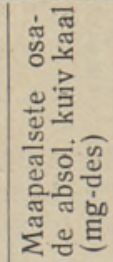 & 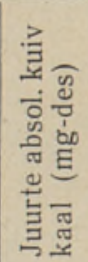 & 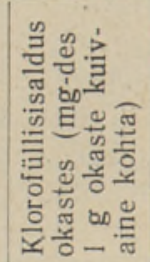 & 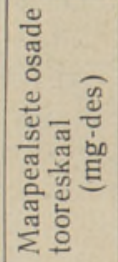 & 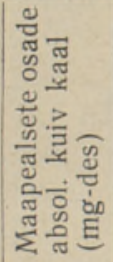 & 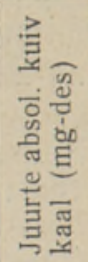 & 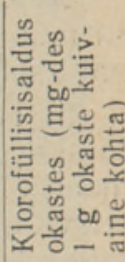 \\
\hline
\end{tabular}

Turvasmuld $A^{*}$

\begin{tabular}{|c|c|c|c|c|c|c|c|c|c|c|}
\hline $\begin{array}{r}20 \\
30 \\
40 \\
50 \\
60 \\
70 \\
80 \\
90 \\
100\end{array}$ & $\begin{array}{l}44,1 \\
54,2 \\
61,2 \\
66,4 \\
70,3 \\
73,4 \\
76,0 \\
78,0 \\
79,8\end{array}$ & $\begin{array}{r}79,0 \\
118,5 \\
158,0 \\
197,5 \\
237,0 \\
276,5 \\
316,0 \\
355,5 \\
395,0\end{array}$ & $\begin{array}{l}36 \\
49 \\
56 \\
63 \\
65 \\
66 \\
68 \\
66 \\
50\end{array}$ & $\begin{array}{l}12 \\
18 \\
19 \\
21 \\
23 \\
23 \\
24 \\
23 \\
22\end{array}$ & $\begin{array}{r}5 \\
8 \\
8 \\
10 \\
11 \\
12 \\
13 \\
11 \\
3\end{array}$ & $\begin{array}{r}15,3 \\
16,7 \\
17,2 \\
18,6 \\
21,1 \\
21,2 \\
20,2 \\
16,8 \\
6,7\end{array}$ & $\begin{array}{r}62 \\
86 \\
101 \\
116 \\
118 \\
119 \\
117 \\
115 \\
112\end{array}$ & $\begin{array}{l}20 \\
29 \\
33 \\
36 \\
39 \\
40 \\
40 \\
39 \\
46\end{array}$ & $\begin{array}{r}8 \\
13 \\
14 \\
17 \\
17 \\
17 \\
19 \\
19 \\
9\end{array}$ & $\begin{array}{r}14,6 \\
14,7 \\
14,9 \\
15,8 \\
17,2 \\
15,9 \\
14,2 \\
13,8 \\
9,5\end{array}$ \\
\hline \multicolumn{11}{|c|}{ Turvasmuld $B^{* *}$} \\
\hline $\begin{array}{r}20 \\
40 \\
60 \\
80 \\
100\end{array}$ & $\begin{array}{l}56,2 \\
71,9 \\
79,3 \\
83,7 \\
86,5\end{array}$ & $\begin{array}{l}128,0 \\
256,0 \\
384,0 \\
512,0 \\
640,0\end{array}$ & $\begin{array}{l}43 \\
55 \\
57 \\
61 \\
45\end{array}$ & $\begin{array}{l}16 \\
20 \\
22 \\
23 \\
19\end{array}$ & $\begin{array}{r}8 \\
10 \\
11 \\
10 \\
3\end{array}$ & $\begin{array}{l}\bar{Z} \\
\overline{-}\end{array}$ & $\begin{array}{l}70 \\
78 \\
96 \\
95 \\
88\end{array}$ & $\begin{array}{l}26 \\
30 \\
36 \\
39 \\
37\end{array}$ & $\begin{array}{r}11 \\
15 \\
16 \\
16 \\
9\end{array}$ & \\
\hline
\end{tabular}

* Tarna-puuturvas, lagunemisaste $70 \%$. Täielik veemahutavus $395 \%$, tuhasus $11,59 \%, \mathrm{pH}=5,21$. Vaimastvere metskonna kuivendatud siirdesoometsa kōige ülemine (vahetult metsakõdu all asetsev) turbakiht.

** Pilliroo-puu-tarnaturvas, lagunemisaste $45 \%$, täielik veemahutavus $640 \%$, tuhasus $8,19 \%, \mathrm{pH}=5,40$. Vaimastvere metskonna kuivendatud siirdesoometsa ülaltoodud turbakihi all asetsev turvas. 
Tabelis toodud andmetest nähtub, et tõusmetele on niiskustingimused kõige optimaalsemad, kui turvasmulla niiskussisaldus on $60-80 \%$ (arvestatult täielikust veemahutavusest). Huvitav on märkida, et täiesti normaalne oli tõusmete pealmaaosade ja juurte arenemine ka $90 \%$-lise niiskuse juures. Veega täieliku küllastumise puhul (100\%) ilmnes aga kõigil juhtudel juurte taandareng ja klorofüllisisalduse järsk langus. Väliselt avaldus see rohelise värvuse kadumises. Siit tuleb järeldada, et turvasmulla niiskussisalduse maksimum, mispuhul noored männid ja kuused kasvada võivad, on mulla veega täielikule küllastatusele veel lähemal kui $90 \%$ (arvestatud täielikust veemahutavusest). Andmetest nähtub, et turvasmulla madala niiskussisalduse ebasoodne mõju ilmneb täiesti selgesti juba $40 \%$-lise niiskussisalduse juures ja on eriti terav $20 \%$ juures.

Analoogilised tulemused ilmnesid tõusmete transpiratsiooni intensiivsuse määramisel kiirkaalumise meetodi abil (Ivanov, Silina ja Tselniker, 1950). Joonisel 2 esitatakse männi ja kuuse kohta transpiratsiooni määramise tulemused.

Uldiselt on teada, et transpiratsiooni intensiivsus on kõige suurem mullaniiskuse optimumi puhul. See peegeldub ka joonisel 2 esitatud transpiratsiooni andmeil, mis omakorda kinnitavad tabeli 2 põhjal tehtud järelduste tõepärasust.

Küsimuse osas - kui suur on turvasmuldades taimedele täiesti kättesaamatuks jääv niiskusvaru - on üldse vähe andmeid. Selle suuruse kindlakstegemiseks viidi samal perioodil

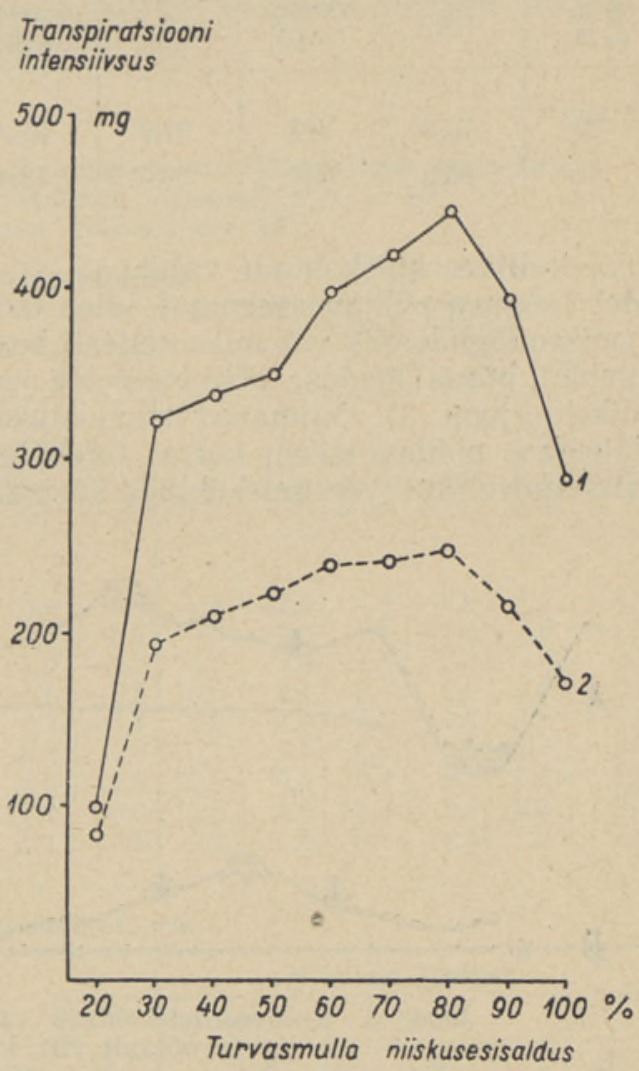

Joon: 2. Männi- ja kuusetōusmete transpiratsiooni intensiivsus (mg-des 1 tunni jooksul $1 \mathrm{~g}$ okaste toorkaalu kohta) turvasmulla mitmesuguse niiskussisalduse juures. läbi närbumisniiskuse määramine männi ja kuuse tõusmete abil (vegetatsiooni meetodil). Tulemused esitatakse tabelis 3 .

Tabelist selgub, et tõusmetele kättesaamatuks jääb küllalt suur niiskushulk, mille suurus üldiselt ühtib seni avaldatud andmetega. Veel selgub, et väiksema lagunemisastme puhul on taimedele kättesaamatu niiskushulk turvasmullas suhteliselt väiksem kui suurema lagunemisastme puhul. Absoluutsetest näitajatest arvestatud närbumisniiskuse protsendid langevad aga omavahel enam-vähem kokku. See on tingitud väiksema lagunemisastmega turvasmulla madalamast kolloidide sisaldusest, sest kolloididel on suur vee kinnihoidmise võime.

Vegetatsioonikatseil saadud andmed on väga olulised turvasmuldades valitsevate niiskustingimuste kvalitatiivse hindamise seisukohalt ja konkreetsete agrotehniliste võtete valikul ning rakendamisel. Eriti on see mak- 
Tabel 3

Kahe erineva lagunemisastme ja veemahutavusega turvasmulla närbumisniiskused (männi ja kuuse tõusmetel)

\begin{tabular}{|c|c|c|c|c|c|c|c|c|}
\hline \multirow{3}{*}{ 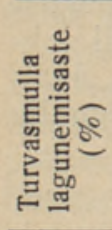 } & \multirow{2}{*}{\multicolumn{2}{|c|}{$\begin{array}{c}\text { Turvasmulla täielik } \\
\text { veemahutav us }\end{array}$}} & \multicolumn{6}{|c|}{ Närbumisniiskused } \\
\hline & & & \multicolumn{3}{|c|}{ Mänd } & \multicolumn{3}{|c|}{ Kuusk } \\
\hline & $\begin{array}{c}\text { kogu- } \\
\text { kaalust } \\
(\%)\end{array}$ & $\begin{array}{c}\text { absoluut- } \\
\text { kuivast } \\
\text { kaalust } \\
(\%)\end{array}$ & $\begin{array}{c}\text { kogu- } \\
\text { kaalust } \\
(\%)\end{array}$ & $\begin{array}{c}\text { absoluut- } \\
\text { kuivast } \\
\text { kaalust } \\
(\%)\end{array}$ & $\begin{array}{c}\text { täielikust } \\
\text { veemahu- } \\
\text { tavusest } \\
\%\end{array}$ & $\begin{array}{c}\text { kogu- } \\
\text { kaalust } \\
(\%)\end{array}$ & $\begin{array}{c}\text { absoluut- } \\
\text { kuivast } \\
\text { kaalust } \\
(\%)\end{array}$ & $\begin{array}{c}\text { täielikust } \\
\text { veemahu- } \\
\text { tavusest } \\
(\%)\end{array}$ \\
\hline 70 & 79,8 & 395 & 37,2 & 59,2 & 15,0 & 37,9 & 61,2 & 15,5 \\
\hline 45 & 86,5 & 640 & 36,0 & 56,3 & 8,8 & 37,8 & 60,8 & 9,5 \\
\hline
\end{tabular}

sev kultiveerimiskohtade valiku ja paigutuse suhtes. Kraavilähedastel aladel (sügava põhjaveeseisuga) tuleb kultiveerida madalamatesse kohtadesse (mikronõgudesse) või mikroreljeefi keskosale. Seevastu aga kraavist kaugemal, pinnalähedase põhjaveeseisu juures tuleb kultiveerida mikrokõrgendikele (joon. 3). Viimased moodustuvad tavaliselt kändude ümber. Pinnalähedase põhjaveeseisu korral tuleb igal juhul loobuda maapinna ettevalmistamisel kultiveerimiskohtade süvendamisest. Tähelepanekud näitavad, et

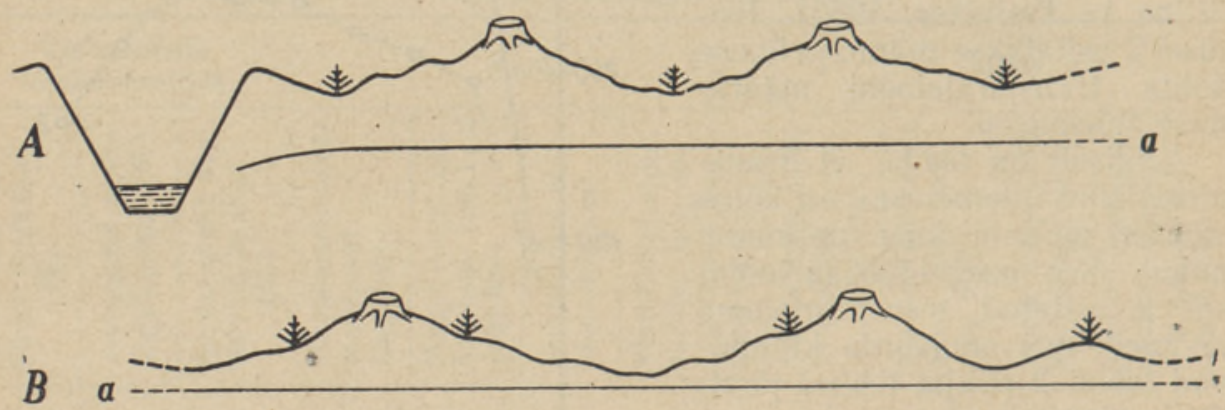

Joon. 3. Kultiveerimiskohtade ratsionaalne asetus tugevalt (A) ja nōrgalt (B) kuivendatud alal.

$a-$ pōhjaveeseis.

mikrokõrgendikele kultiveerimine on vajalik tingimustes, kus põhjaveetase on maapinnale ligemal kui $15-20 \mathrm{~cm}$. Täiesti lubamatu on niisugusel juhul maapinna süvendamine, mis tekib tahes-tahtmata eespoolmainitud tavalist maapinna ettevalmistusviisi kasutades.

Temperatuuritingimused maapinnal ja pinnalähedases õhukihis. Metsakultuuride kasvamamineku ja arengu seisukohalt on kõige olulisemad vegetatsiooniperioodil esinevad äärmustemperatuurid, mis põhjustavad vastavalt kuuma või külma kahjustusi. Selles osas on tingimused kuivendatud siirdesoometsade lageraiealadel ebasoodsad. Juba Kollisti (1953) mikroklimaatilised uurimused kamardunud raielankidel Sõmerpalu metskonnas näitasid, et suvekuudel tõuseb päevane temperatuur maapinnal sageli üle $50^{\circ}-60^{\circ} \mathrm{C}$ ja võib langeda öösel alla $0^{\circ} \mathrm{C}$. Veel näitasid Kollisti uurimused, et temperatuuritingimused on halvemad kraavilähedastel tugeva kuivendusega aladel, kus tingituna kuiva mulla väiksemast soojusmahutavusest ja soojusjuhtimisest kuumeneb ja jahtub pindmine mullakiht rohkem 
ja kiiremini. Temperatuuritingimusi muutis tunduvalt ekstreemsemaks maapinda kattev kõrreliste kulu.

1953. la. vegetatsiooniperioodil teostati meie poolt pidevaid mikroklimaatilisi vaatlusi Vaimastvere metskonnas asuval kuivendatud siirdesoometsa värskel raielangil (raiumisjärgsel suvel). Vaatluste koondandmed esitatakse tabelis 4 .

Tabelist nähtub, et surnud kate oma isoleeriva toime tõttu halvendab temperatuuritingimusi. Kraavilähedasel alal olid need kõige halvemad surnud samblakihiga kaetud vaatluskohas ja tunduvalt paremad lapil, kus oli kõrvaldatud nii sambla kui ka toorhuumuse kiht.

Tabel 4

Maapinnal esinevad miinimum- ja maksimumtemperatuurid (dekaadi keskmised) kuivendatud siirdesoometsa raielangil raiumisjärgsel aastal (1953. a. Kurista mm. Vaimastvere mk.)

Miinimumtemperatuurid

\begin{tabular}{|c|c|c|c|c|c|c|c|c|c|c|c|c|c|}
\hline \multirow[b]{3}{*}{ Kuu } & \multirow[b]{3}{*}{ 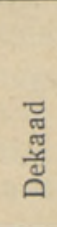 } & \multicolumn{6}{|c|}{ Kraavi lähedal } & \multicolumn{6}{|c|}{ Kraavist kaugel } \\
\hline & & \multicolumn{2}{|c|}{$1^{\star}$} & \multicolumn{2}{|c|}{$2^{\star}$} & \multicolumn{2}{|c|}{$3^{*}$} & \multicolumn{2}{|c|}{$1^{*}$} & \multicolumn{2}{|c|}{$2^{\star}$} & \multicolumn{2}{|c|}{$3^{\star}$} \\
\hline & & 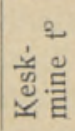 & 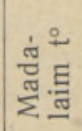 & 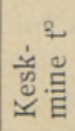 & 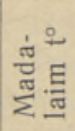 & 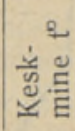 & 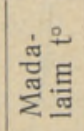 & 总咅 & 离 & 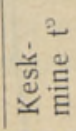 & 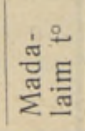 & 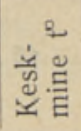 & 㲾 \\
\hline Mai & II & 1,3 & $-4,7$ & 1,1 & $-4,5$ & 0,8 & $-7,1$ & 2,4 & $-2,0$ & 2,4 & $-2,6$ & 1,9 & $-1,6$ \\
\hline Jüni & III & $\begin{array}{l}2,2 \\
6.5\end{array}$ & $\begin{array}{r}-3,1 \\
\end{array}$ & 1,6 & $-3,5$ & 0,7 & $-5,6$ & $\begin{array}{l}4,3 \\
8,3\end{array}$ & $-1,6$ & 3,3 & $-1,5$ & 3,0 & $-2,1$ \\
\hline " & II & $\begin{array}{l}0,0 \\
9,0\end{array}$ & $\begin{array}{r}1,0 \\
-0,8\end{array}$ & $\begin{array}{l}3,0 \\
8,1\end{array}$ & $\begin{array}{l}-0,6 \\
-2,2\end{array}$ & $\begin{array}{l}5,0 \\
7,5\end{array}$ & $\begin{array}{l}-1,2 \\
-3,5\end{array}$ & $\begin{array}{r}8,3 \\
10,6\end{array}$ & $\begin{array}{l}4,0 \\
3,1\end{array}$ & $\begin{array}{l}7,4 \\
9,7\end{array}$ & $\begin{array}{l}3,2 \\
1,6\end{array}$ & $\begin{array}{l}7,2 \\
9,6\end{array}$ & $\begin{array}{l}2,5 \\
1,0\end{array}$ \\
\hline & III & 5,8 & 1,8 & 4,1 & $-0,7$ & 3,3 & $-1,8$ & 7,9 & 4,0 & 7,8 & 4,4 & 6,7 & 2 , \\
\hline Ju & I & 8,4 & 3 , & 7,2 & 0, & 6,3 & 0,3 & 10,1 & 5,7 & 9,1 & 4, & 8 , & 3 , \\
\hline$"$ & W & 8,6 & 3,5 & 7,6 & 0,7 & 6.6 & $-0,2$ & 10,9 & 6,5 & 10,9 & 5 , & 8,8 & 4,6 \\
\hline$"$ & III & 12,5 & 2,7 & 12,6 & 0,6 & 12,1 & 0,0 & 12,6 & 6,0 & 11,4 & 5 , & 9,8 & 2 , \\
\hline August & I & 7,1 & 2,6 & 5,8 & 0,4 & 5,1 & -0 & 9,2 & & & 4,5 & 7,0 & \\
\hline
\end{tabular}

Maksimumtemperatuurid

\begin{tabular}{|c|c|c|c|c|c|c|c|c|c|c|c|c|c|}
\hline \multirow[b]{3}{*}{ Kuu } & \multirow[b]{3}{*}{ 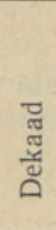 } & \multicolumn{6}{|c|}{ Kraavi lähedal } & \multicolumn{6}{|c|}{ Kraavist kaugel } \\
\hline & & \multicolumn{2}{|c|}{$1^{\star}$} & \multicolumn{2}{|c|}{$2^{\star}$} & \multicolumn{2}{|c|}{$3^{\star}$} & \multicolumn{2}{|c|}{$1^{\star}$} & \multicolumn{2}{|c|}{$2^{\star}$} & \multicolumn{2}{|r|}{$3^{\star}$} \\
\hline & & 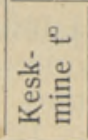 & 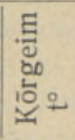 & 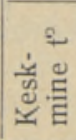 & 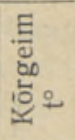 & 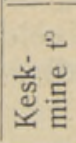 & $\begin{array}{l}\text { E } \\
0 \\
o 0 \\
\text { o. } \\
: 0\end{array}$ & 总递 & 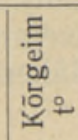 & 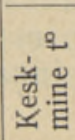 & 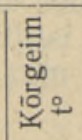 & 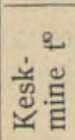 & $\begin{array}{l}\text { 톨 } \\
\infty \\
\text { on } \\
\underline{10}\end{array}$ \\
\hline Mai & II & 34,2 & 47,0 & 33,1 & 41,1 & & & 26,2 & 32,3 & 26,5 & & & 38,5 \\
\hline & III & 31,2 & 43,1 & 28,9 & 43,6 & 36,2 & 54,0 & 25,9 & 33,0 & 26,9 & 34,1 & 25,8 & 32,3 \\
\hline Juun & I & 33,5 & 41,0 & 33,1 & 43,1 & 41,6 & & 30,8 & & 30,0 & & & 38 \\
\hline$"$ & A & 32,0 & 45,1 & 31,7 & 43 & 40,3 & 57 & 29,9 & 37 & 30,4 & 38 , & 29,6 & 38 \\
\hline & III & 36,2 & 40,3 & 38,7 & 43 & 51,6 & 57 & 34,2 & & 35,6 & & & 38,1 \\
\hline & II & 32,2 & $\begin{array}{l}40,9 \\
30 ?\end{array}$ & $\begin{array}{l}33,6 \\
32\end{array}$ & 42, & 42,8 & & $\begin{array}{l}30,9 \\
0 \times 7\end{array}$ & 37 & 32,0 & & & 37,5 \\
\hline & III & 3 & 39 , & $\begin{array}{l}5,0 \\
35,8\end{array}$ & $\begin{array}{l}42, \\
41 .\end{array}$ & $\begin{array}{l}38,8 \\
42,7\end{array}$ & & $\begin{array}{l}28,7 \\
31,7\end{array}$ & & $\begin{array}{l}29,5 \\
33,4\end{array}$ & $\begin{array}{l}37,7 \\
37,7\end{array}$ & $\begin{array}{l}30,5 \\
34,1\end{array}$ & $\begin{array}{l}36,1 \\
40,2\end{array}$ \\
\hline August & 1 & 27,6 & 32,7 & 28,7 & 34,0 & 32,4 & 42,2 & 25,4 & 30,8 & 26,4 & 33,1 & 27,5 & 33,1 \\
\hline
\end{tabular}

\footnotetext{
1* Lapp $(0,7 \times 0,7 \mathrm{~m})$, millelt oli maakirvega kõrvaldatud nii sambla kui ka toorhuumuse kiht.

2* Lapp $(0,7 \times 0,7 \mathrm{~m})$, millelt oli kōrvaldatud vaid samblakiht (toorhuumus säilitati).

s* Ettevalmistamata maapind, mis kraavi lähedal oli kaetud kuivanud roheliste sammaldega ja kraavist kaugel peaasjalikult turbasammaldega.
} 
Kõrged temperatuurid maapinnal avaldavad mõju peamiselt tõusmetele (külvitaimedele). Vegetatsiooniperioodil esinevad öökülmad kahjustavad külve ja kuuse puhul ka istutusi. Seejuures külmakahjustused ilmnevad nende noortel kasvudel. Multamäki (1942) järgi kahjustab külm kuuse võrseid, kui temperatuur langeb alla $-2,8^{\circ} \mathrm{C}$. Kuid külmakahjustused ei võta võimalust kuuse edukaks kasvatamiseks käsitletavatel aladel. Temperatuuritingimused on kõige raskemad maapinnal ja pinnalähedases õhukihis (umbes $0,5 \mathrm{~m}$ ). Pärast sellest kihist väljakasvamist võib kuusk oma kasvu edukalt jätkata, ja nagu eespool nägime, suurt puidutoodangut anda. Seepärast tuleb siingi eelistada istutust külvile.

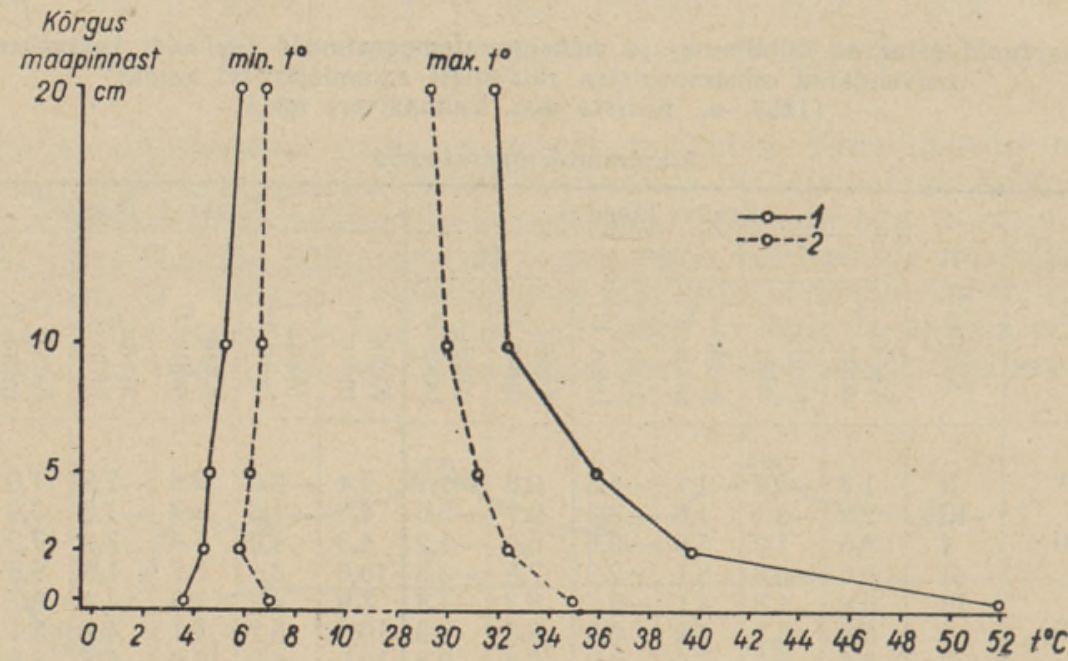

Joon. 4. Keskmised miinimum- ja maksimumtemperatuurid (21. VI kuni 29. V.I 1953) maapinnal $(0 \mathrm{~cm})$ ning $2 ; 5 ; 10$ ja $20 \mathrm{~cm}$ kõrgusel õhus Vaimastvere metskonna kuivendatud siirdesoometsa raielangil raiumisjärgsel suvel erineval kaugusel kraavist. 1 - kraavi lähedal (põhjavesi $25 \mathrm{~cm}$ sügavusel); 2 - kraavist kaugel (põhjavesi $6 \mathrm{~cm}$ sügavusel).

Lähtudes külmakahjustuse ohust, tuleb kuuse puhul kasutada võimalikult suuremat istutusmaterjali, mis loob eeldused kiireks väljajõudmiseks külmaohtlikust, maapinnalähedasest õhukihist.

Tabel 5

Keskmised miinimum- ja maksimumtemperatuurid maapinnal ning 20, 50 ja $100 \mathrm{~cm}$ kõrgusel õhus Vaimastvere metskonna kuivendatud siirdesoometsa raielangil erineval kaugusel kraavist (21. VII-30. VII 1953)

\begin{tabular}{c|c|c|c|c|c|c|c|c}
\hline \multirow{2}{*}{$\begin{array}{c}\text { Vaatlus- } \\
\text { punkti } \\
\text { asend }\end{array}$} & \multicolumn{3}{|c|}{ Miinimumtemperatuurid } & \multicolumn{4}{|c|}{ Maksimumtemperatuurid } \\
\cline { 2 - 8 } & 0 & 20 & 50 & 100 & 0 & 20 & 50 & 100 \\
\hline $\begin{array}{c}\text { Kraavi } \\
\text { lähedal* }\end{array}$ & 41,4 & 29,9 & 28,4 & 27,7 & 9,8 & 10,5 & 10,8 & 11,0 \\
$\begin{array}{c}\text { Kraavist } \\
\text { kaugel** }^{*}\end{array}$ & 31,8 & 28,8 & 27,7 & 26,7 & 10,8 & 11,0 & 11,0 & 11,3
\end{tabular}

* Põhjavesi $25 \mathrm{~cm}$, maapind kaetud kuivanud samblakihiga.

** Pōhjavesi $10 \mathrm{~cm}$, maapind kaetud turbasamblaga, 
Joonisel 4 ja tabelis 5 toodud keskmistest näitajatest selgub, et kuivanud samblakihiga isoleeritud maapinnal (kraavi lähedal) on nii miinimumkui ka maksimumtemperatuurid ebasoodsamad kui pinnalähedases õhukihis. Soojust paremini juhtiva turbasambla katte puhul on see kehtiv maksimumtemperatuuride kohta, kuid öösel võib pinnalähedase õhukihi temperatuur langeda madalamale kui maapinnal, mis saab alt soojust juurde.

Katsekultuurid. Ökoloogiliste tingimuste analüüsi põhjal tehtud järelduste kontrollimiseks ja praktikale sobivate kultuuride rajamise konkreetsete meetodite leidmiseks rajati kuivendatud siirdesoometsade lageraietele Oru, Vaimastvere ja Sõmerpalu metskonnas 1953. a. kevadel katsekultuurid.

Kultiveeritavate puuliikidena kasutati mändi ja kuuske. Maapinna ettevalmistamise viiside katsetamisel oli peaeesmärgiks külmakohrutuskindla viisi väljaselgitamine. Selleks võrreldi põhiliselt nelja maapinna ettevalmistusviisi.

1. Nn. tavaline viis, mille puhul maapind valmistati ette maakirvega 0,7 $\times 0,7 \mathrm{~m}$ suuruste lappidena koos kamara (metsakõdukihi) kõrvaldamisega ja lapi põhja kobestamisega kuni $15 \mathrm{~cm}$ sügavuselt. Lappide tavalisest suuremaid mõõte kasutati suurt rohukasvu silmas pidades.

2. Rehaga kõrvaldati $0,7 \times 0,7 \mathrm{~m}$ lappidelt vaid sammalkate. Alles jäi selle all asuv vähelagunenud metsakõdu kiht. Lapi põhi jäi puutumata. Seda viisi kasutati ainult värsketel raiestikel (Oru ja Vaimastvere metskonnas), kuna kamardunud aladel ei ole see läbiviidav.

3. Maapind jäeti täiesti ette valmistamata. Tähistati ainult kultiveerimiskohad.

4. Istutusaukude valmistamine labidaga (koolitatud kuusetaimede istutamiseks).

Kultiveerimisviisi osas katsetati istutamist ja külvi. Istutusmaterjalina kasutati kõigi maapinna ettevalmistamisviiside puhul kahe aasta vanuseid kuuse ja männi seemikuid, mida istutati kiillabidaga. Ettevalmistamata maapinna puhul kasutati veel 4-aastasi koolitatud kuusetaimi, mida istutati labidaga valmistatud aukudesse, peale selle ka kiillabida või poolpuuri abil.

Kultiveerimistulemusi oli võimalus jälgida nende juurdumise staadiumis (1953. ja 1954. aastal).

Erinevate maapinna ettevalmistusviisidega rajatud kultuuride võrdlemine näitas, et ülalkirjeldatud viisidest esimene (nn. tavaline viis) kui ka labidaga istutusaukude valmistamine ei sobi metsakultuuride rajamiseks antud tingimustes (joon. 5, variandid $\mathrm{V}$ ja VI, tabelid 6 ja 7 ). Peamise põhjusena võib ette tuua külmakohrutuse suuri kahjustusi sel teel rajatud kultuurides. Kraavist kaugemal olevatel nõrgemini kuivendatud aladel kannatasid kultuurid lisaks sellele kultiveerimiskoh-

Joon. 5. 1953. a. kevadel istutamise teel Oru $\mathrm{m} / \mathrm{k}$. kuivendatud siirdesoometsa värskele raielangile rajatud katsekultuuride kordaminek (säilinud elujôuliste taimede \%) ja viimase aasta kasvu keskmine pikkus (cm-tes) 1954. a. sügisel. 1 - mänd; 2 - kuusk; 3 - viimase aasta juurdekasv. Köigi! variantidel, peale $\mathrm{XV}$, kasutati istutamisel kaheaastasi seemikuid, var. XV puhul koolitatud taimi. Maapind valmistati ette var. V ja VI - tavalisel viisil; var. XI ja XII - raudrehaga; var. XIII, XIV ja XV jäeti maapind täiesti ette valmistamata.

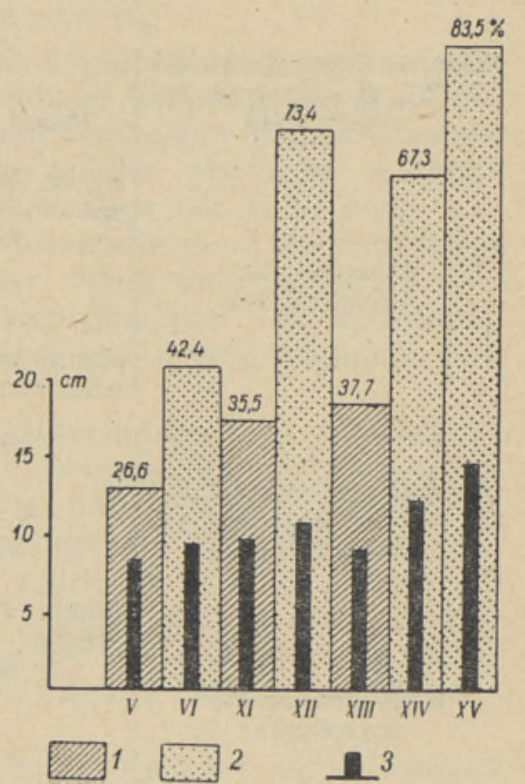


tade süvendamise läbi, mis kutsus esile vee kogunemise lappidesse ja halvendas seeläbi omakorda kultuuride seisundit.

Tabel 6

Labidaga valmistatud aukudesse istutatud kuuse koolitatud taimede kordaminek Vaimastvere metskonna kuivendatud siirdesoometsa raiestikul

\begin{tabular}{|c|c|c|c|c|c|c|}
\hline \multirow{2}{*}{ Kuivendusaste } & \multicolumn{3}{|c|}{$\begin{array}{l}\text { Kordaminek protsentides } \\
\text { 1953, a. sügisel }\end{array}$} & \multicolumn{3}{|c|}{$\begin{array}{c}\text { Kordaminek protsentides } \\
\text { 1954. a. sügisel }\end{array}$} \\
\hline & $\begin{array}{l}\text { Elujõot- } \\
\text { lisi }\end{array}$ & $\begin{array}{l}\text { Kirat- } \\
\text { sevaid }\end{array}$ & $\begin{array}{l}\text { Hukku- } \\
\text { nuid }\end{array}$ & $\begin{array}{l}\text { Elujōu- } \\
\text { lisi }\end{array}$ & $\begin{array}{l}\text { Kirat- } \\
\text { sevaid }\end{array}$ & $\begin{array}{c}\text { Hukku- } \\
\text { nuid }\end{array}$ \\
\hline $\begin{array}{l}\text { Tugevamini kuivendatud } \\
\text { (põhjavesi umbes } 25 \mathrm{~cm} \\
\text { sügavusel) } \\
\text { Nôrgalt kuivendatud } \\
\text { (pôhjavesi umbes } 10 \mathrm{~cm} \\
\text { sügavusel) }\end{array}$ & 91,5 & 4,6 & 3,9 & 51,5 & 26,7 & $\begin{array}{r}21,8 \\
73,6\end{array}$ \\
\hline
\end{tabular}

Paremaid tulemusi andis maapinna ettevalmistamine teisena toodud viisil (rehaga kõrvaldati vaid samblakiht) (joon. 5, variandid XI ja XII). Sel juhul kohrutuse kahjustusi peaaegu ei esinenud, samuti olid hoopis väiksemad nõrgemini kuivendatud alal liigniiskuse kahjustused. Sellele tuleb veel kasuks asjaolu, et maapinna ettevalmistamisel rehaga on roh-

Tabel 7

Sõmerpalu metskonna kuivendatud siirdesoodele 1953. a. kevadel rajatud katsekultuuride kordaminek 1954. a. sügisel

\begin{tabular}{c|c|c|c}
\hline $\begin{array}{c}\text { Maapinna ettevalmis- } \\
\text { tamise viis }\end{array}$ & $\begin{array}{c}\text { Kultiveeritav puuliik, } \\
\text { kultiveerimismaterjal ja } \\
\text { kultiveerimisvis }\end{array}$ & $\begin{array}{c}\text { Kordaminek } \\
\text { (säilinud elu- } \\
\text { jōuliste } \\
\text { taimede \%) }\end{array}$ & $\begin{array}{c}\text { Taimede välja- } \\
\text { langemise } \\
\text { peamine pöhjus }\end{array}$ \\
\hline
\end{tabular}
$0,7 \times 0,7 \mathrm{~m}$ lappidena tavalisel viisil

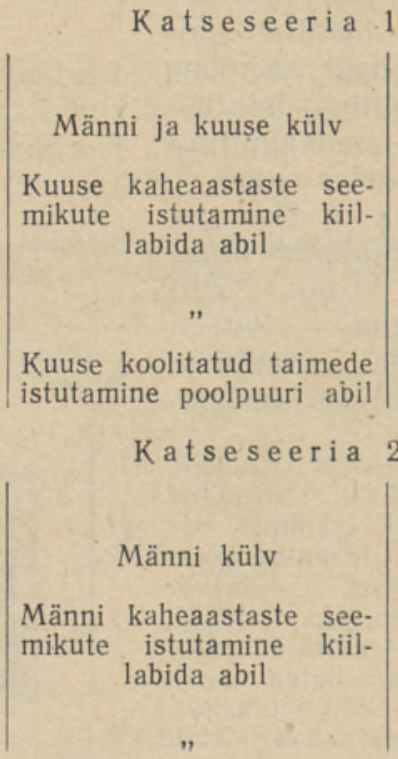

Täielikult hukkunud

Külmakohrutus

Maapind ette
valmistamata

,

Maapind ette valmistatud $0,7 \times 0,7 \mathrm{~m}$ lappidena tavalisel viisil

Ettevalmistamata maapinnale
"

Täielikult hukkunud

Külmakohrutus 
kem võimalusi mikrokõrgendikele kultiveerimiseks. Tavalist viisi kasutades aga tuleb otsida kändude vahel madalamaid kohti, kus leidub vähem juuri. Esimesel aastal oli selle viisi puhul külvide idanemine väiksem (eriti tugevamini kuivendatud alal) kui tavalisel viisil valmistatud lappidel. Selle pồhjuseks tuleb pidada halvemaid idanemistingimusi metsakõdu pealmises kihis, mis sageli on tingitud kuivusest ja seemnete puudulikust katmisest vähelagunenud metsakõduga. Vähelagunenud turbasammalpadjandite ja turba esinemise korral oli külvide kordaminek ja areng nendel rahuldav. Sügis- ja kevadperioodil esinenud külmakohrutuse tagajärjel olid järgmiseks aastaks ka külvide puhul selgunud selle viisi paremused tavalise viisi ees:

Häid tulemusi andis istutamine täiesti ettevalmistamata maapinnale (joon. 5, var. XIII, XIV ja XV; tabel 7), mispuhul kohrutamise nähtusi üldse ei esinenud. Mõningaid raskusi tekitas värskeil raiestikel istutuse nõuetekohane läbiviimine, s. o. istutusvigade vältimine. Tuli hoolega jälgida, et osa juuri ei jääks pinda katva kuiva samblakihi sisse.

Väiksema istutusmaterjali (seemikute) puhul olid värskeil raiestikel (joon. 5) täiesti ettevalmistamata maapinnal tulemused halvemad kui maapinnal, kust samblakiht oli kõrvaldatud. Samuti oli kärsakate poolt kahjustatud seemikute protsent ettevalmistamata maapinna puhul suurem. Seepärast on soovitav värskeil naiestikel eemaldada kultiveerimiskohalt pealmine kuiv samblakiht (eriti väiksemate seemikute korral) ja tingimata kasutada kärsakavastaseid tõrjeabinõusid.

Kultuuride inventeerimine näitas, et ettevalmistamata maapinna puhul annab väga häid tulemusi kuuse koolitatud taimede istutamine kas kiillabida (joon. 5, var. XV) või poolpuuri abil. Poolpuuriga istutamist kasutati Sõmerpalu metskonnas kuivendatud siirdesool juba kamardunud alal (tabel 7). Viimasel juhul asetati istutamisel puuriga väljatõstetud mätas pärast taime kohalepaigutamist tervelt tagasi oma endisele kohale, nii et kamar jäi puutumata. Seejuures istutatud taim jäi tekkinud augu seina ja tagasiasetatud mätta vahele. Mõlemat istutamisviisi kasutades saavutati käsitletavail ıaladel kultuuri hea kordaminek. Seevastu kuuse koolitatud taimede istutused labidaga valmistatud aukudesse kannatasid tugevasti külmakohrutuse all ja ei andnud rahuldavaid tulemusi. Eriti halb oli nende kultuuride seisund nõrgalt kuivendatud alal (tabel 6).

Kuivendatud siirdesoode lageraietel omab perspektiive maapinna ettevalmistamisel herbisiidide kasutamine. Kirjanduses toodud andmeil on võimalik herbisiididega maapinda töödeldes kaotada rohukasv paariks aastaks ja kauemakski. Sellega võib saavutada kaks põhilist eesmärki: 1) mulla puutumata jätmise teel oleks välditud külmakohrutuse oht ja 2) oleks kõrvaldatud puutaimede lämmatamise võimalus taimkatte poolt kultuuri kõige kriitilisemas arengujärgus (juurdumise faasis). Kuna seda maapinna ettevalmistamise võimalust ei ole käsitletavail kasvukohtadel veel katsetatud, tuleks seda tingimata teha kõige lähemal ajal, et positiivsete tulemuste korral see kohe rakendada tootmispraktikasse.

Siinjuures tuleb veel kord rõhutada kultiveerimiskohtade tähistamise vajalikkust. Katsekultuuride puhul selgus, et ilma selleta on võimatu nii kultuuride seisukorra jälgimine kui ka nende nõuetekohane hooldamine. Nagu juba eespool märgiti, peab seda tegema tugevate keppidega, mis ulatuksid maa seest välja ca $3 / 4 \mathrm{~m}$. Kogemused näitavad, et kultiveerimiskohtade arv ühel hektaril ei tarvitse olla üle 2000-3000, kuna liitunud puistute tekkimist neil kasvukohtadel kindlustab sookase rohkearvuline looduslik uuendus. Kultiveeritud puuliigi huvides tuleb viimase hulka edaspidi hooldusraietega reguleerida.

Suurt tähtșust kultuuride kordamineku kịndlustamisel omab istutus- 
materjali kvaliteet. Kuuse kaheaastaste seemikutega ettevalmistamata maale teostatud istutuse hukkumine Sõmerpalu metskonna katsealal (tabel 7) oli tingitud peamiselt istutusmaterjali nõrkusest, sest. seemikud ei suutnud vastu panna vohava rohttaimestiku (põdrakanep ja kõrrelised) lämmatavale toimele. Kultuuride rajamisel ja inventeerimisel saadud kogemused näitavad, et kuivendatud siirdesoode lageraietele tuleb kultuurid rajada tugeva, suuredimensioonilise ja terve istutusmaterjaliga (kuuse puhul nelja-aastaste koolitatud taimedega, männi puhul tugevate, vähemalt kaheaastaste seemikutega).

Kultuuride hooldamine seisneb peamiselt rohu eemaldamises kultiveeritud puutaimede ümbrusest. Seda on soovitav teostada põimamise teel. Rohttaimede väljakiskumine koos juurtega võib esile kutsuda ka kultiveeritud puutaimede juurte vigastamise ja kohrutamise ohu. Väga raske on kultuuride hooldamine külvi teel rajatud kultuurides, mis peab piirduma rohttaimede põimamisega külvitaimede kohal ja ümber. Seejuures omavad mõningaid eeliseid tihedad külvid, mis takistavad rohttaimede tungimist külvikohale.

Eesti NSV Teaduste Akadeemia

Zooloogia ja Botaanika Instituut
Saabus toimetusse 30. XI 1955

\section{KIRJANDUS}

H a in la, V., 1955. Männi, kuuse ja sookase tootlikkusest kuivendatud siirdesoodel. «Sotsialistlik Pōllumajandus» nr. 5.

Kollist, P., 1953. Kuivendamise mōju üleminekusoometsade uuenemistingimustele. Loodusuurijate Seltsi juubelikoguteos. Tallinn.

Mult a mäki, S. E., 1942. Kuusen taimien paleltuminen ja sen vaikutus ojitettujen soiden metsittymiseen. Acta Forestalia Fennica 51.

Ив анов Л. Н., Силин а А. Н. и Цельнике р Ю. Л., 1950. О методе быстрого взвешивания для определения транспирации в естественных условиях. «Ботанический журнал», т. XXXV, № 2.

\section{ЭКОЛОГИЧЕСКИЕ УСЛОВИЯ СПЛОШНЫХ ВЫРУБОК ЛЕСОВ ОСУШЕННЫХ ПЕРЕХОДНЫХ БОЛОТ И ПОДХОДЯЩИЕ К НИМ СПОСОБЫ РАЗВЕДЕНИЯ ЛЕСНЫХ КУЛЬТУР}

\section{У. Р. РИИСПЕРЕ}

Резюме

Главными объектами лесных осушительных работ на территории Эстонской ССР являются леса переходных болот, где осушки широко проводились уже в конце прошлого и в начале нынешнего столетия. В результате осушки значительно увеличится продуктивность лесов переходных болот, причем это увеличение вполне зависит от состава древостоев. Исследования Хайнла (1955) показывают, что хорошо продуцирующими породами на осушенных переходных болотах можно считать сосну и ель, в то время как береза пушистая по сравнению с ними в несколько раз менее продуктивна. Поэтому на таких площадях следует создавать древостои с господством сосны и ели.

Использование спелых лесов осушенных переходных болот происходит по способу сплошных рубок. Қак показывают исследования 
К̈оллиста (1954) и данные авторра, этй сплошные вырубки возобновляются естественно главным образом пушистой березой. Вследствне малой продуктивности пушистой березы, такая смена пород нежелательна, и для разведения более продуктивных древостоев на таких сплошных вырубках следует заложить культуры сосны и ели.

Лесокультурная практика показывает, что добиться успехов при закладке культур хвойных пород на вырубках лесов осушенных переходных болот крайне трудная задача вследствие имеющихся там неблагоприятных экологических условий - мощности травяного покрова, опасности выжимания морозом, неудовлетворительных условий влажности, экстремальных температур на земле и в приземном слое воздуха и наличия вредителей. В связи с тем в культурах, заложенных обыкновенными способами (посевом или посадкой в площадки, приготовленные мотыгами с последующим взрыхлением верхнего слоя), нередки случаи низкого процента приживаемости или даже сплошной гибели.

В первом году после рубки вымирают зеленые мхи и тенелюбивая травяная растительность, и уже во втором вегетационном периоде вырубки покрываются густым и высоким травяным покровом, в котором господствуют злаки (молиния, лесной вейник, щучка, полевица и др.), иванчай, малина и другие виды растений.

Учитывая состав и динамику появления растительности, следует закультивировать лесосеки немедленно после рубки, причем посадка предпочтительнее посева, а при проведении ее следует применять более крупные и мощные саженцы, чтобы создать растениям благоприятные условия для более быстрого преодоления зоны влияния сорной растительности.

В зависимости от физических свойств торфяных почв, культуры (как посевы, так и посадки), заложенные по обыкновенному способу, страдают от выжимания весенними заморозками. Для предотвращения этой опасности нужно отказаться от обыкновенного способа подготовки почвы, который состоит в обнажении, углублении и взрыхлении почвы, и культуры нужно закладывать на неподготовленную почву или же можно ограничиться удалением только верхнего слоя мохового покрова.

Условия влажности почвы на сплошных вырубках лесов осушенных переходных болот не одинаковы - вблизи канав и на возвышениях микрорельефа в верхних слоях почвы встречаются условия недостаточной влажности, повреждающие главным образом только посевы, дальше же от канав, где уровень грунтовой воды выше, повреждения от избыточной влажности часты и опасны для посадок. Опыты, проведенные для установления минимального, оптимального и максимального процента влажности для роста молодой сосны и ели, показали, что самый оптимальный процент лежит в пределах от 60 до 80 (считая от полной влагоемкости торфяной почвы).

Явные признаки регресса наблюдались у всходов на торфяной почве, вполне насыщенной водой. Влажность завядания, которую определили у всходов сосны и ели на торфяной почве со степенью разложения $70 \%$ (с влагоемкостью $395 \%$ ), была от 15 до $15,5 \%$ от полной влагоемкости (т. е. $37,2-37,9 \%$ от общего и $59,2-61,2 \%$ от абсолютносухого веса почвы); на торфяной почве 45 -процентного разложения (с влагоемкостью $64,0 \%$ ) влажность завядания была от 8,8 до $9,5 \%$ от полной влагоемкости $(36,0-37,8 \%$ от полного и $56,3-60,8 \%$ от абс. сухого веса почвы).

В зависимости от различных условий влажности при подборе мест для площадок нужно использовать микрорельеф - вблизи канав культивировать на более низкие места, при высоком же уровне грунтовой воды по возможности на микровозвышения (около пней). 
На сплошных вырубках лесов осушенных переходных болот часто бывают неблагоприятные для культур экстремальные температуры на земле и в приземном слое воздуха. На площадях, близких к канавам, особенно при наличии изолирующего покрова (сухого мха или прошлогодней травы), температура на поверхности земли часто повышается до $50^{\circ} \mathrm{C}$ и больше, а ночью падает ниже нуля. От высоких температур страдают главным образом посевы (молодые всходы), между тем как температуры ниже нуля могут повреждать и посадки ели. Во избежание отрицательного влияния неблагоприятных температурных условий приходится также предпочитать посадку посеву. При посадке ели желательно применять посадочный материал с возможно большей надземной частью, ввиду того, что это способствует более скорому преодолению приземного слоя воздуха, опасного ночными морозами.

Данные анализа опытных культур, заложенных на сплошных вырубках лесов осушенных переходных болот, подтверждают заключения, сделанные на основании исследования мест произрастания. По опытным культурам можно сделать вывод, что посадки более успешны, чем посевы. Посадки дают лучшие результаты на неподготовленной почве при использовании микрорельефа. Только на свежих вырубках целесообразно (при посадочном материале малых размеров) устранять с площадок слой сухого мха. Сосна дает лучшие результаты при применении мощных сеянцев. При посадке ели непременно нужно сеянцам предпочитать 4-летние саженцы. Для посадки как сеянцев, так и еловых саженцев с успехом можно воспользоваться мечом Колесова (при посадке саженцев и полубуравом, если вынутые глыбы вложить обратно в ямки). Необходимой оказывается маркировка мест (площадок) посадки.

Ннститут зоологии и ботаники Академии наук Эстонской ССР

Поступила в редакцию 30 XI 1955

\section{ÖKOLOGISCHE BEDINGUNGEN DER KAHLSCHLAGFLÄCHEN ENTWÄSSERTER UBERGANGSMOORWÄLDER UND IHNEN ENTSPRECHENDE WALDKULTURMETHODEN}

\section{U. RIISPERE}

\section{Zusammenfassung}

Die in der Estnischen Sozialistischen Sowjetrepublik längst (vor 40-70 Jahren) entwässerten Obergangsmoorwälder bestehen hauptsächlich aus Kieferbeständen der III (II-IV) Bonität (wo in geringem Masse auch Fichte und Moorbirke vorkommen). Nach dem Kahlschlag findet ein Holzartenwechsel statt, die Kahlschlagflächen verjüngen sich natürlich mit der Moorbirke. Da die Moorbirke im Vergleich mit der Fichte und der Kiefer auf entwässerten Ubergangsmooren beträchtlich weniger produktiv ist, erscheint die Entstehung von Moorbirkenbeständen als unerwünscht. Um den ungünstigen Holzartenwechsel zu vermeiden, sind die Kahlschlagflächen mit Fichte und Kiefer künstlich zu verjüngen.

Die Praxis der künstlichen Waldverjüngung und Untersuchungen der Standortsverhältnisse zeigen, dass die Anlage gedeihlicher Nadelholzkulturen auf Kahlschlagflächen längst entwässerter Ubergangsmoorwälder sehr 
kompliziert ist. Das Wachstum der Anpflanzungen behindern hauptsächlich folgende ungünstige Faktoren: 1) rasch entstehende üppige Kräutervegetation (blaues Pfeiffengras, Rasenschmiele, Sumpfstraussgras, Rohr-Reitkraus, Waldweidenröschen, Himbeere u. a.); 2) Auffrieren des Bodens (an gelockerten Plätzen); 3) oft ungünstige Bodenfeuchtigsverhältnisse (auf schwach entwässerten Flächen ist der Boden zu nass); 4) ungünstige tägliche Temperaturminima und Temperaturmaxima an der Bodenoberfläche und in der Luft unmittelbar über dem Boden (auf stark etnwässerten und mit Streu bedeckten Flächen). Der genannten Faktoren wegen misslingen des öfteren die mit gewöhnlichen Methoden angelegten Nadelholzkulturen (Saat oder Pflanzung mit vorhergehendem Entfernen des Rasens oder der Streudecke, nebst Lockerung des Bodens).

Versuche zeigen, dass auf den Kahlschlagflächen entwässerter Ubergangsmoorwälder die Pflanzungen im Vergleich mit den Saaten erfolgreicher sind. Gute Ergebnisse erweist die Spaltpflanzung mit dem Keilspaten in unvorbereiteten Boden. Auf jungen Kahlschlagflächen ist es zweckmässig, die Entfernung der Streudecke von den Pflanzstellen ohne Lockerung durchzuführen. An Orten mit niedrigem Grundwasserspiegel sind Mikroerhebungen auszunutzen. Für Kieferpflanzung benutze man starke 2jährige Saatpflanzen, für Fichtenpflanzung verschulte $2 \times 2$ Jahre alte Pflanzen. Des üppigen Krautwuchses wegen müssen die Pflanzstellen markiert werden.

Institut für Zoologie und Botanik

der Akademie der Wissenschaften der Estnischen SSR
Eingegangen am 30. Nov. 1955 